\title{
Comparative evaluation of pancytopenia/bicytopenia in adult and pediatric population in a tertiary care centre through hematological parameters and bone marrow studies
}

\author{
Asbah Shams ${ }^{1}$, Pooja Agarwal ${ }^{2, *}$, Arpita Joshi ${ }^{3}$, Prashant Prakash $^{4}$ \\ ${ }^{1,3}$ Junior Resident, ${ }^{2,4}$ Associate Professor, ${ }^{2,3}$ Dept. of Pathology, ${ }^{4}$ Dept. of Medicine, ${ }^{2,3,4}$ Sarojini Naidu Medical College, Agra, \\ Uttar Pradesh, India
}

*Corresponding Author:

Email: drpooja.agarwal@gmail.com

\begin{abstract}
Introduction: Pancytopenia/bicytopenia is not a disease per se rather a spectrum of changes pertaining to reduction in cell numbers. Its presentation as well as causes are diverse in adult and pediatric population. It is imperative to evaluate the causes of pancytopenia/bicytopenia in adults and pediatric subjects as well as to understand the significant differences in their etiology and manifestations.

Aims and objectives: Comparative evaluation of pancytopenia/bicytopenia in adult and pediatric patients through hematological parameters and bone marrow studies.

Materials and Methods: In this study, 80 adult and 40 pediatric patients of pancytopenia/bicytopenia were evaluated. Detailed history, examination, Hb, TLC, platelet count, MCV, PBS examination, Bone marrow studies were performed. Statistical analysis was done using one-way anova.

Result: The commonest presenting age in children was between 12-16 years of age and 19-40 years in adults. Male to female ratio in adults was 1.94:1, while that of pediatric patients was 1:0.74. On bone marrow examination, most common cause of pancytopenia/bicytopenia among pediatric subjects was aplastic anemia (32.5\%) followed by megaloblastic anemia(20\%), acute leukemia $(17.5 \%)$, erythroid hyperplasia (15\%). Megaloblastic anemia was the commonest cause of pancytopenia/bicytopenia among adult cases $(37.5 \%)$ followed by erythroid hyperplasia (20\%) and aplastic anemia (10\%).

Conclusion: Our study concludes that there is statistically significant difference between the values of Hb, TLC, Platelet and MCV among adult and pediatric patients of pancytopenia; implying that these hematologic parameters vary with respect to mean values and range between the two groups. We also conclude nutritional deficiency to be a common cause of pancytopenia in both the age groups.
\end{abstract}

Keywords: Aplastic anemia, Megaloblastic anemia, Pancytopenia.

\section{Introduction}

Pancytopenia is defined as haemoglobin level < $13.5 \mathrm{~g} / \mathrm{dl}$ in males and $11.5 \mathrm{~g} / \mathrm{dl}$ in females; the leucocyte count $<4 \times 10^{9} / 1$; and the platelet count $<$ $150 \times 10^{9} / 1 .{ }^{1}$ Bicytopenia is reduction in any of the two cell lines. Pancytopenia/bicytopenia is not a disease per se rather a spectrum of changes pertaining to reduction in cell numbers; either because of reduced production, increased destruction, or due to peripheral pooling in spleen. It usually presents as weakness, lethargy, recurrent infections or bleeding tendencies. The causes of pancytopenia span both neoplastic and nonneoplastic entities. The latter frequently involves nutritional deficiencies which are comparatively easy to diagnose and treat than neoplastic entities like leukemias. Hence timely intervention in a case of pancytopenia/bicytopenia is of utmost importance.

The presentation as well as causes of pancytopenia are diverse and different in adult and pediatric population. It is imperative to perform detailed clinical examination, history taking and complete haematological work-up including bone marrow studies to evaluate the causes of pancytopenia/bicytopenia in adults and pediatric subjects as well as to understand the significant differences in their etiology and manifestations. Very few of such comparative studies were done previously. Hence, this study was undertaken to evaluate pancytopenia/bicytopenia in adult and pediatric patients through haematological parameters and bone marrow studies and to statistically compare their outcome.

\section{Materials and Methods}

All patients presenting with pancytopenia/bicytopenia to the Department of Pathology, between June 2015 to June 2017, were selected for the study. Patients between 0-18 years of age were considered pediatric while more than 18 years of age were considered as adults. A total of 120 patients were included in our study, out of which 80 were adults and pediatric group constituted 40 patients.

Patients with at least two of the following findings were included in the study:

1. Hemoglobin $<13.5 \mathrm{gm} / \mathrm{dl}$ in males or $11.5 \mathrm{gm} / \mathrm{dl}$ in females

2. Total Leucocyte count $<4000 / \mu \mathrm{L}$

3. Platelet count $<1,50,000 / \mu \mathrm{L}$

Exclusion criteria:

1. Patients on myelotoxic chemotherapy. 
2. Patients who were unco-operative or who did not give consent for the study.

3. Patients in whom bone marrow examination was contra-indicated.

Detailed clinical history regarding generalized weakness, fever, bleeding tendencies and other symptoms was taken. Examination was done and pallor, hepato-splenomegaly, lymphadenopathy, petechiae were assessed. Blood was withdrawn in EDTA for peripheral blood smear examination and Complete blood count, Hemoglobin, Total Leucocyte count, Differential Leucocyte count, Platelet count, Mean Corpuscular volume, Mean corpuscular haemoglobin and Mean corpuscular hemoglobin concentration were studied. Bone marrow aspiration was done subsequently using $16 \mathrm{G}$ needle and smears fixed in methanol and stained with May Grunwald Giemsa(MGG). The smears were assessed under the following headings:

1. Cellularity

2. Myeloid to Erythroid ratio

3. Erythropoiesis

4. Myelopoiesis

5. Megakaryopoiesis

6. Lymphocytes and plasma cells

7. Hemoparasites

Bone marrow biopsy was done as $\&$ when required.

Statistical analysis was done using one-way anova (analysis of variance) and p-value $<0.05$ was considered significant.

\section{Results}

This study was undertaken in the pathology department of S. N. Medical College, Agra between
June 2015 and June 2017. A total of 130 cases presented with the clinical diagnosis of pancytopenia/bicytopenia, out of which 120 cases were selected for the study.10 cases were excluded as they had one of the exclusion criteria. Out of 120 cases 80 were adults and 40 pediatric ones. Among adults, most common age group was 19-40 years with maximum cases between 20-29 years of age $(23.75 \%)$ and the median age was 33 years. The most common age range in children was $12-16$ years of age $(42.5 \%)$ and the median age was 14 years. Children $<1$ year of age constituted the least common age group.

There was a male predominance among adult patients with male to female ratio being 1.94:1. Among pediatric patients, male to female ratio was1:0.74, reflecting a slight male predominance.

On clinical history, generalized weakness was the most common symptom among both adults $(68.75 \%)$ and pediatric subjects (75\%). It was followed by fever, seen in $61.25 \%$ adults and $70 \%$ among children. On physical examination, the commonest sign was pallor in both adults (100\%) and children (85\%), followed by splenomegaly $(43.75 \%$ in adults and $37.5 \%$ in children). Other findings were hepatomegaly ( $20 \%$ in adults, $32.5 \%$ in children), lymphadenopathy $(12.5 \%$ in adults and $7.5 \%$ in children) and bleeding tendencies like epistaxis, menorrhagia $(13.75 \%$ in adults and $12.5 \%$ in children).

\section{Haematological Profile}

In this study we studied the range of Hemoglobin, Total leucocyte count, Platelet count and Mean corpuscular volume of adult and pediatric patients. These results were compared using one way anova test.

Table 1: Range of haemoglobin

\begin{tabular}{|c|c|c|c|c|}
\hline \multirow{2}{*}{$\begin{array}{l}\text { Haemoglobin } \\
\text { (g/dl) }\end{array}$} & \multirow{2}{*}{\multicolumn{2}{|c|}{$\begin{array}{c}\text { No. or cases } \\
\text { Adult }\end{array}$}} & No. of cases & Percentage \\
\hline & & & \multicolumn{2}{|c|}{ Pediatric } \\
\hline $1-4$ & 19 & $23.75 \%$ & 7 & $17.5 \%$ \\
\hline $4-7$ & 47 & $58.75 \%$ & 19 & $47.5 \%$ \\
\hline $7-10$ & 11 & $13.75 \%$ & 10 & $25 \%$ \\
\hline$>10$ & 3 & $3.75 \%$ & 4 & $10 \%$ \\
\hline Grand Total & 80 & $100 \%$ & 40 & $100 \%$ \\
\hline
\end{tabular}

Table 2: Range of total leucocyte count

\begin{tabular}{|l|c|c|c|c|}
\hline \multirow{2}{*}{$\begin{array}{c}\text { TLC } \\
\text { (cells/cumm) }\end{array}$} & No. of cases & Percentage (in \%) & No. of cases & Percentage \\
\cline { 2 - 5 } Adult & \multicolumn{2}{c|}{ Pediatric } \\
\hline$<1000$ & 1 & $1 \%$ & 1 & 2.5 \\
\hline $1000-2499$ & 34 & $42 \%$ & 10 & 25 \\
\hline $2500-4000$ & 19 & $24 \%$ & 13 & 32.5 \\
\hline$>4000$ & 26 & $33 \%$ & 16 & 40 \\
\hline Grand Total & 80 & $100 \%$ & 40 & $100 \%$ \\
\hline
\end{tabular}


Table 3: Range of platelet count

\begin{tabular}{|l|c|c|c|c|}
\hline \multirow{2}{*}{$\begin{array}{l}\text { Platelet count } \\
\text { (cells/mm }\end{array}$} & No. of cases & $\begin{array}{c}\text { Percentage } \\
\text { (in \%) }\end{array}$ & No. of cases & Percentage \\
\cline { 2 - 5 } & \multicolumn{2}{|c|}{ Adult } & \multicolumn{2}{|c|}{ Pediatic } \\
\hline$<50,000$ & 46 & $57 \%$ & 22 & 55 \\
\hline $50,000-99,999$ & 22 & $28 \%$ & 12 & 30 \\
\hline $1,00,000-1,50,000$ & 09 & $11 \%$ & 5 & 12.5 \\
\hline$>1,50,000$ & 3 & $4 \%$ & 1 & 2.5 \\
\hline Grand Total & 80 & $100 \%$ & 40 & $100 \%$ \\
\hline
\end{tabular}

Table 4: Comparison of haematological parameters between adult and pediatric subjects having pancytopenia/bicytopenia

\begin{tabular}{|l|l|l|l|l|}
\hline & \multicolumn{1}{|c|}{ Hb (gm/dl) } & \multicolumn{1}{|c|}{ TLC (cells/cumm) } & Platelet count (cells/cumm) & \multicolumn{1}{|c|}{ MCV (fl) } \\
\hline Adult & Mean: 5.41875 & Mean: 16971.3 & Mean: 56387.5 & Mean: 100.455 \\
& Range $: 1.4-10.8$ & Range $: 500-1,73,000$ & Range $: 10000-280000$ & Range :66.9-141.5 \\
\hline Pediatric & Mean: 6.335 & Mean: 21625 & Mean: 58835 & Mean: 92.3275 \\
& Range $: 1.8-11.4$ & Range $: 600-333000$ & Range $: 7400-350000$ & Range :63-132.8 \\
\hline
\end{tabular}

On comparing MCV, adult patients showed macrocytosis with majority of the cases (46\%) having MCV greater than $101 \mathrm{fl}$. While in pediatric patients, $27.5 \%$ had MCV > 101fl. Most of the paediatrics patients (47.5\%) had MCV within normal range (83-101 fl). This could be attributed to the fact that megaloblastic anemia was the commonest finding in adults while children had aplastic anemia as the commonest cause.

The mean values of haemoglobin, TLC, platelet count and MCV were compared between adult and pediatric subjects using one way anova test. Upon comparison, the difference was found to be statistically significant with p-value less than 0.05. [Table 1-4]

\section{PBS Findings}

On peripheral blood smear examination, the most common finding was anisocytosis seen in $94 \%$ adult cases and $80 \%$ pediatric cases followed by macrocytic blood picture (45\% in both adult and pediatric). Microcytosis was noted in $10 \%$ adult cases and $7.5 \%$ pediatric cases while $28 \%$ adult cases and $37.5 \%$ pediatric cases showed normocytic picture. $17 \%$ adult cases and $10 \%$ pediatric cases had dimorphic picture. Hyper-segmented neutrophils were noted in 30\% adult and $15 \%$ pediatric cases. This again was due to the fact that megaloblastic anemia was seen more frequently in adults than paediatrics patients. Circulating blasts were seen in $18.75 \%$ adult cases and $17.5 \%$ pediatric cases. Circulating immature cells, apart from blasts, (which included myelocytes, metamyelocytes and band forms) were seen in $8.75 \%$ adult cases (6 cases of CML in accelerated phase and 1 case of megaloblastic anemia) and one case of CML in pediatric subjects.

\section{Bone marrow studies}

On bone marrow examination, most common cause of pancytopenia/bicytopenia among pediatric subjects was aplastic anemia (32.5\% of all cases) followed by megaloblastic anemia(20\%). While in adults megaloblastic anemia constituted $37.5 \%$ of all cases and was the commonest cause of pancytopenia/bicytopenia. [Table 5, 6]

Bone marrow biopsy was performed in 22 adults and 17 pediatric cases. Among adult patients, 5 cases of megaloblastic anemia, 2 cases of erythroid hyperplasia, 2 cases of multiple myeloma, 1 case of CML, 3 cases of AML, 6 cases of aplastic anemia and 1 case of normal marrow and 2 cases of dry tap underwent biopsy. The biopsy findings were found to be consistent with that of aspiration. In two cases of dry tap on aspiration, biopsy was performed and reticulin stain was done. In 1 case grade 2 and in other case grade 3 fibrosis was observed which confirmed the diagnosis of myelofibrosis. In pediatric subjects, biopsy was performed in all (13) cases of aplastic anemia and histology was found to be consistent with that of aspitation. Biopsy performed in 2 cases of AML, 1 case of ITP and 1 case of NHL was concordant with that of aspiration findings. Hence, the cases in which biopsy was performed, it was found to be $100 \%$ concordant with aspiration while in cases of aplastic anemia and dry tap it aided in the diagnosis.

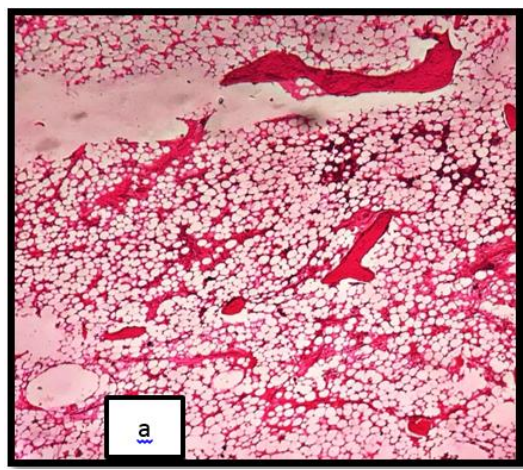

Fig. 1: bone marrow biopsy smear from a case of aplastic anemia showing hypocellular marrow spaces 


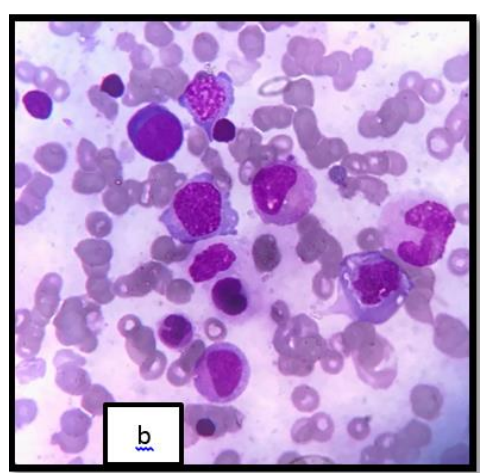

Fig. 2: bone marrow aspirate smear from a case of megaloblastic anemia showing megaloblasts and one giant band form

Table 5: Bone marrow aspirate findings in pediatric subjects

\begin{tabular}{|l|c|c|}
\hline \multicolumn{1}{|c|}{ Diagnosis } & No. of cases & Percentage \\
\hline Aplastic anemia & 13 & $32.5 \%$ \\
\hline Megaloblastic anemia & 8 & $20 \%$ \\
\hline Acute leukemia & 7 & $17.5 \%$ \\
\hline Erythroid hyperplasia & 6 & $15 \%$ \\
\hline ITP & 2 & $5 \%$ \\
\hline CML & 1 & $2.5 \%$ \\
\hline IDA & 1 & $2.5 \%$ \\
\hline NHL & 1 & $2.5 \%$ \\
\hline Normal marrow & 1 & $2.5 \%$ \\
\hline
\end{tabular}

Table 6: Bone marrow aspirate findings in adult subjects

\begin{tabular}{|l|c|c|}
\hline \multicolumn{1}{|c|}{ Final diagnosis } & No. of cases & Percentage (in \%) \\
\hline Megaloblastic Anemia & 30 & $37.5 \%$ \\
\hline Erythroid Hyperplasia & 16 & $20 \%$ \\
\hline Aplastic Anemia & 08 & $10 \%$ \\
\hline CMPN, consistent with CML & 06 & $7.5 \%$ \\
\hline AML & 05 & $6.25 \%$ \\
\hline AMML & 02 & $2.5 \%$ \\
\hline ALL & 02 & $2.5 \%$ \\
\hline Normal marrow & 03 & $3.75 \%$ \\
\hline Iron deficiency anemia & 02 & $2.5 \%$ \\
\hline CLL & 02 & $2.5 \%$ \\
\hline Multiple Myeloma & 02 & $2.5 \%$ \\
\hline Dry tap & 02 & $2.5 \%$ \\
\hline Grand Total & 80 & $100 \%$ \\
\hline
\end{tabular}

\section{Discussion}

In our study of 120 patients of pancytopenia/bicytopenia, there were 80 adults $(67 \%)$ and 40 pediatric patients $(33 \%)$. Jha $\mathrm{A}$ et $\mathrm{al}^{2}$ also encountered $72 \%$ of adult patients in their study. Among adult population, most of the patients were in the age group of 19-40 years with maximum cases between 20-29 years of age (23.75\%). The most common age of presentation in children was between $12-16$ years of age $(42.5 \%)$. Thus the most common age of presentation was 12-30 years which is in concordance with Khode $\mathrm{K}$ et al. ${ }^{3}$ There was a strong male predominance among adult patients with male to female ratio being 1.94:1. Male predominance was also reported by Khode $\mathrm{K}$ et $\mathrm{al}^{3}$ and Jha $\mathrm{A}$ et $\mathrm{al}^{2}$ Among pediatric patients, male to female ratio was1:0.74, reflecting a slight male predominance.

In our study, generalised weakness was the most common symptom followed by fever. Chandra $\mathrm{K}$ et $\mathrm{al}^{4}$ also reported weakness as the commonest presenting symptom. Naseem $\mathrm{S}$ et $\mathrm{al}^{5}$ and Khode $\mathrm{K}$ et $\mathrm{al}^{3}{ }^{3}$ however, reported fever to be the most common presenting symptom.

Pallor was seen in $100 \%$ adult and $85 \%$ pediatric patients in our study which is in condordance with Khode $\mathrm{K}$ et $\mathrm{al}^{2}$ and Chandra $\mathrm{K}$ et al. ${ }^{6}$ Naseem $\mathrm{S}$ et al, ${ }^{5}$ however, reported a lower percentage of pallor in study of pediatric population. 
On PBS examination,anisocytosis was the most common finding as is reported by Nassem $\mathrm{S}$ et $\mathrm{al}^{5}$ and Chandra $\mathrm{K}$ et al. ${ }^{4}$

In our study, megaloblastic anemia was the most common cause of pancytopenia/bicytopenia in adult patients. This is in concordance with the findings of Chandra $\mathrm{K}$ et $\mathrm{al}^{4}$ and Khodke $\mathrm{K}$ et al. ${ }^{3}$ Aplastic anemia was the commonest finding in paediatric patients $32.5 \%$ cases. Naseem S et $\mathrm{al}^{5}$ and Gupta $\mathrm{V}$ et $\mathrm{al}^{6}$ also reported aplastic anemia as the commonest cause of pancytopenia in children. Bhatnagar SK et al, ${ }^{7}$ however, found megaloblastic anemia to be the commonest cause of pancytopenia in children. Megaloblastic anemia came out to be the most common cause of pancytopenia/bicytopenia in our study and other previous studies. This reflects a great prevalence of nutritional deficiency which should be identified and treated to reduce the economic burden and to prevent unnecessary investigations. There should be education regarding eating habits and nutritional values of various foods.

Other studies have not calculated age wise predominance of etiology. However, most studies have reported megaloblastic anemia followed by aplastic anemia as the commonest cause of pancytopenia. We also found megaloblastic anemia followed by erythroid hyperplasia and aplastic anemia as the most common etiologies.

Mean Hemoglobin, TLC, Platelet count of adult population in our study was $5.4 \mathrm{gm} / \mathrm{dl}, 16971 / \mathrm{mm}^{3}$, $56387 / \mathrm{mm}^{3}$ respectively. Chandra $\mathrm{K}$ et $\mathrm{al}^{4}$ have also calculated mean values of these parameters. Their mean $\mathrm{Hb}$ was $5.9 \mathrm{gm} / \mathrm{dl}$ which is in concordance with our study. Their mean TLC was 2300 cell $/ \mathrm{mm}^{3}$ which is lower than our study. This could be because we encountered 6 cases of CML in accelerated phase which had a very high TLC. Their reported mean platelet count was slightly lower than our study. Similar studies on mean values of these haematological parameters have not been done in pediatric patients.

\section{Conclusion}

In this study, on comparing the various hematologic indices $(\mathrm{Hb}$, TLC, Platelet and MCV) between adult and pediatric patients of pancytopenia/bicytopenia, we found that the difference between these values was statistically significant. The mean values of haemoglobin and platelet were slightly lower and TLC was higher among adult patients of pancytopenia than that of pediatric ones. The latter was probably due to more number of CML cases among adults. Our study also shows a high prevalence of nutritional deficiency in cases of pancytopenia/bicytopenia, which should be rectified with nutritional supplements and education regarding feeding habits.

Funding: No funding sources.

Conflict of interest: None declared.

\section{References}

1. Mahapatra M. Pancytopenia; Aplastic anemia. In: Saxena R, Pati HP, Mahapatra M, editors.de Gruchy's ClinicalHematology in Medical Practice, $6^{\text {th }}$ ed. New Delhi: Wiley; 2013:106.

2. Jha A, Sayami G, Adhikari RC, Panta AD, Jha R. Bone marrow examination in cases of pancytopenia. J Nepal Med Assoc 2008;47:12-7.

3. Khodke K, Marwah S, Buxi G, Yadav RB, Chaturvedi NK. Bone Marrow Examination in cases of pancytopenia. J Indian Acad Clin Med 2001;2(1,2):55-9.

4. Chandra K, Kumar P. Morphological Spectrum of Bone Marrow in Pancytopenia - a retrospective study in a Tertiary Care Centre. J Evolution Med Dent Sci 2014;3(4):1056-64.

5. Naseem S, Varma N, Das R, Ahluwalia J, Sachdeva MU, Marwaha RK. Pediatric patients with bicytopenia/pancytopenia: Review of etiologies and clinico-hematological profile at a tertiary center. Indian $J$ Pathol Microbiol 2011;54:75-80.

6. Gupta V, Tripathi S, Tilak V, Bhatia BD. A study of clinico-haematological profiles of pancytopenia in children. Trop Doct 2008;38:241-3.

7. Bhatnagar SK, Chandra J, Narayan S, Sharma S, Singh V, Dutta AK. Pancytopenia in children: Etiological profile. $J$ Trop Pediatr 2005;51:236-39.

How to cite this article: Shams A., Agarwal P., Joshi
A., Prakash P. Comparative evaluation of
pancytopenia/bicytopenia in adult and pediatric
population in a tertiary care centre through
hematological parameters and bone marrow studies. J
Diagn Pathol Oncol 2018;3(4):290-94.

